\title{
Functional Polymers. VII. On the C(3)-Control of Stereo- chemistry in Asymmetric Reactions Catalyzed by Polymeric Cinchona Alkaloids*
}

\author{
Norio KOBAYASHI and Kiyoko IWAI \\ Sagami Chemical Research Center, \\ Nishi-Ohnuma 4-4-1, Sagamihara, Kanagawa 229, Japan.
}

(Received August 8, 1980)

\begin{abstract}
Asymmetric reactions of dodecanethiol with $\beta$-substituted phenyl vinyl ketones were studied using polymeric and monomeric cinchona alkaloids as chiral catalysts. The mode of stereoregulation (C(8), $\mathrm{C}(9)$-control, $\mathrm{C}(3)$-control) varied depending not only on the substituents at $\mathrm{C}(3)$ and $\mathrm{C}\left(6^{\prime}\right)$ of the alkaloid molecule but also on the $\beta$-substituent of the unsaturated systems. The $C(3)$-control was observed when the steric environments of the enantioface differentiating step were sufficiently crowded (combination of polymer catalyst and bulky $\beta$-substituent).
\end{abstract}

KEY WORDS Asymmetric Reaction / Polymer Catalyst / Cinchona Alkaloid / Stereochemistry / Thiol / $\alpha, \beta$-Unsaturated Compound /

Recently, we reported on the asymmetric thiol addition to $\alpha, \beta$-unsaturated systems catalyzed by acrylonitrile-cinchona alkaloid copolymers (ANCA) ${ }^{1-3}$ Two types of reactions have been studied. One is the reaction in which a chiral carbon is created at the $\alpha$-position in the step of proton addition (Type I), and the other is the reaction in which an asymmetric center is induced at the $\beta$ position in the step of $\mathrm{S}-\mathrm{C}$ bond formation (Type II). The stereochemistry of the Type I

Type I RSH $+\mathrm{CH}_{2}=\mathrm{CR}^{\prime} \mathrm{X}$<smiles>[R]C([X])C[Se][Ba][Ca]</smiles>

Type II $\mathrm{RSH}+\mathrm{R}^{\prime} \mathrm{CH}=\mathrm{CHX}$<smiles>[X]CC([R])[R3]([H])=[W]#N</smiles>

reactions, such as dodecanethiol-isopropenyl methyl ketone ${ }^{1}$ and benzyl mercaptan-methyl $\alpha$-phthalimidoacrylate, ${ }^{2}$ was found to be controlled by the configurations at $\mathrm{C}(8)$ and $\mathrm{C}(9)$ in the alkaloid moieties of AN-CA ("C(8), C(9)-control"), as is

* For Part VI of this series, see ref 3.
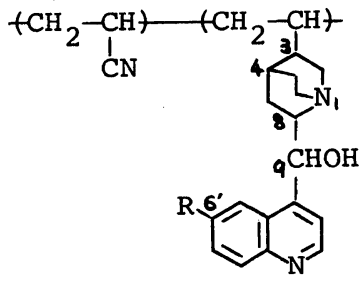

AN-CA

\begin{tabular}{llllll}
\hline & & \multicolumn{4}{c}{ Configuration } \\
\cline { 3 - 6 } CA & $\mathrm{R}$ & $\mathrm{C}(3)$ & $\mathrm{C}(4)$ & $\mathrm{C}(8)$ & $\mathrm{C}(9)$ \\
\hline \multirow{2}{*}{ QN } & OMe & $R$ & $S$ & $S$ & $R$ \\
QD & OMe & $R$ & $S$ & $R$ & $S$ \\
CD & H & $R$ & $S$ & $S$ & $R$ \\
CN & H & $R$ & $S$ & $R$ & $S$ \\
\hline
\end{tabular}

generally observed in the asymmetric reactions under the influence of cinchona alkaloids (CA) or their derivatives. ${ }^{4-12}$ On the other hand, the reaction of benzyl mercaptan with 2-nitrostyrene ${ }^{3}$ (Type II) gave always an excess of (+)-enantiomer, irrespective of the kind of alkaloid residue in AN-CA. This phenomenon can be explained in terms of the chiral force stemming from $\mathrm{C}(3)$ being 
greatly reinforced by a large substituent (polymer chain) so that it exceeds the chiral force stemming from $C(8)$ and $C(9)$, which would otherwise be stronger than that from $\mathrm{C}(3)$ (" $\mathrm{C}(3)$-control").

With a view to obtaining a greater understanding of the nature of the $\mathrm{C}(3)$-control, we have investigated other Type II reactions. In this paper, we report on the asymmetric addition of thiols to $\beta$ substituted aryl vinyl ketones catalyzed by the polymeric and monomeric alkaloids,

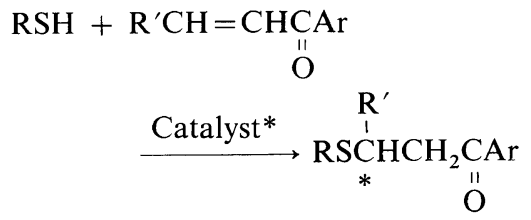

\section{EXPERIMENTAL}

\section{Materials}

Quinine (QN), quinidine (QD), cinchonidine (CD), and cinchonine $(\mathrm{CN})$ were commercial reagents and used without further purification. Dihydroquinine (DHQN), ${ }^{12}$ dihydroquinidine (DHQD) ${ }^{12}$ dihydrocinchonidine (DHCD), ${ }^{1}$ dihydrocinchonine $(\mathrm{DHCN}),{ }^{1}$ and $\mathrm{AN}-\mathrm{CA}$ copolymers ${ }^{13}$ including $\mathrm{AN}-\mathrm{QN} \cdot \mathrm{HCl}$ (acrylonitrile-quinine hydrochloride copolymer), AN-QNBC (acrylonitrile1-benzylquininium chloride copolymer), and $\mathrm{AN}$ QNEC (acrylonitrile-9-O-ethoxycarbonylquinine copolymer) were prepared as previously reported. Dodecanethiol (I) and $p$-chlorothiophenol were obtained commercially and distilled before use. Triphenylmethanethiol (Aldrich) was used as received. 2,6-Di-t-butyl-4-mercaptophenol was synthesized according to the method of Fujisawa and coworkers ${ }^{14} \mathrm{mp} 87-89^{\circ} \mathrm{C}$ (hexane) (lit. ${ }^{14} \mathrm{mp} 87$ $88^{\circ} \mathrm{C}$ ). Chalcone (IIb) was obtained commercially and recrystallized from petroleum ether. Crotonophenone (IIc) was obtained commerically and distilled. Other unsaturated ketones were synthesized by stirring an equimolar mixture of an aldehyde and an aryl methyl ketone in a diluted ethanol solution of sodium hydroxide. 2'Methoxychalcone: bp $167-174^{\circ} \mathrm{C}(0.1 \mathrm{mmHg}) .4^{\prime}-$ Chlorochalcone: $\mathrm{mp} 99-100^{\circ} \mathrm{C}(\mathrm{EtOH})\left(\right.$ lit. $^{15} \mathrm{mp}$ $\left.100^{\circ} \mathrm{C}\right) .4^{\prime}$-Nitrochalcone: $\mathrm{mp} 141-146^{\circ} \mathrm{C}(\mathrm{EtOH})$ (lit. ${ }^{15} \mathrm{mp} 146^{\circ} \mathrm{C}$ ). $\beta$-Phenyl-2-acrylonaphthone: $\mathrm{mp}$ $106-108^{\circ} \mathrm{C}$ (EtOH) (lit. $\left.{ }^{16} \mathrm{mp} 105-106^{\circ} \mathrm{C}\right)$. 4Methylchalcone: $\mathrm{mp} 98-98.5^{\circ} \mathrm{C}$ (EtOH) (lit. ${ }^{17} \mathrm{mp}$
96.5 $5^{\circ} \mathrm{C}$. 4-Methoxychalcone: $\mathrm{mp} \quad 73.4-74^{\circ} \mathrm{C}$ (EtOH) (lit. $\left.{ }^{18} \mathrm{mp} 77-78^{\circ} \mathrm{C}\right) .2$-Methoxychalcone (IIa): $\mathrm{mp} 55.5-56^{\circ} \mathrm{C}$ (petroleum ether) (lit. ${ }^{19} \mathrm{mp}$ $58-59^{\circ} \mathrm{C}$ ). 2-Nitrochalcone: $\mathrm{mp} \quad 122-125^{\circ} \mathrm{C}$ (aq $\mathrm{AcOH})\left(\right.$ lit. $^{15} \mathrm{mp} 128-130^{\circ} \mathrm{C}$ ). The solvents were purified by the usual methods.

\section{Measurements}

Optical rotations were measured in benzene at $25^{\circ} \mathrm{C}$ with a Union PM-201 automatic digital polarimeter. IR spectra were recorded on a Hitachi EPI-G3 grating infrared spectrophotometer. ${ }^{1} \mathrm{H}$ nuclear magnetic resonance (NMR) spectra of the products were recorded on a Varian T-60 NMR spectrometer. For determining the enantiomeric excess $(\%$ ee) of IIIa, a Varian HA-100 NMR spectrometer was used.

\section{Asymmetric Reactions}

The asymmetric reactions were carried out by stirring a mixture of a thiol $(5.0 \mathrm{mmol})$, an $\alpha, \beta$ unsaturated compound $(6.25 \mathrm{mmol})$, and a catalyst $(0.125 \mathrm{mmol})$ in a solvent $(30 \mathrm{ml})$ at room temperature under $\mathrm{N}_{2}$ for several days. The results are summarized in Tables II-VI. The physical properties and analytical data of the reaction products, $\gamma$ ketosulfides, are listed in Table I. The following sections describe typical reaction procedures. Column chromatography was carried out on silica gel with benzene.

Asymmetric Addition of $\mathbf{I}$ to Ila. A mixture of $1.01 \mathrm{~g}$ of I, $1.49 \mathrm{~g}$ of IIa, and $0.10 \mathrm{~g}$ of AN-QN (9.7) (acrylonitrile-QN copolymer containing $9.7 \mathrm{~mol} \%$ of QN units) in $30 \mathrm{ml}$ of toluene was stirred for 7 days at room temperature under $\mathrm{N}_{2}$ and then filtered. The filtered catalyst was washed with toluene and dried. The recovered copolymer weighed $0.09 \mathrm{~g}$. Evaporation of the combined filtrate and the toluene washings under reduced pressure followed by column chromatography of the residue afforded $0.24 \mathrm{~g}(11 \%$ yield $)$ of IIIa: $[\alpha]_{\mathrm{D}}+14.0^{\circ}(c$, $\left.4.42 \mathrm{gl}^{-1}\right)(18 \% \mathrm{ee}) ; \mathrm{mp} 28^{\circ} \mathrm{C}(\mathrm{MeOH}) ;$ IR 1690 $\mathrm{cm}^{-1}\left(v_{\mathrm{C}=\mathrm{o}}\right)$; NMR $\left(\mathrm{CDCl}_{3}\right) \delta 0.8-1.8(\mathrm{~m}, 23 \mathrm{H}$, $\left.\mathrm{C}_{11} \mathrm{H}_{23}\right), 2.46\left(\mathrm{t}, J=7 \mathrm{~Hz}, 2 \mathrm{H}, \mathrm{CH}_{2} \mathrm{~S}\right), 3.55$ (d, $\left.J=7 \mathrm{~Hz}, 2 \mathrm{H}, \mathrm{CH}_{2} \mathrm{CO}\right), 3.83\left(\mathrm{~s}, 3 \mathrm{H}, \mathrm{CH}_{3} \mathrm{O}\right), 4.98(\mathrm{t}$, $J=7 \mathrm{~Hz}, 1 \mathrm{H}, \mathrm{CHS}), 6.7-8.0 \mathrm{ppm}(\mathrm{m}, 9 \mathrm{H}$, aromatic protons). The analytical data are listed in Table I.

When dimethylformamide (DMF) was used as the reaction medium in place of toluene, the reaction was carried out for one day. The reaction 


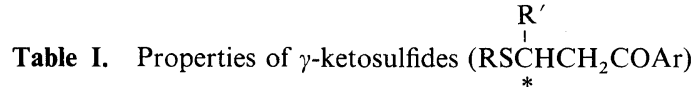

\begin{tabular}{|c|c|c|c|c|c|c|}
\hline \multirow{2}{*}{$\mathrm{R}$} & \multirow{2}{*}{$\mathrm{R}^{\prime}$} & \multirow{2}{*}{$\mathrm{Ar}$} & mp (bp) & \multicolumn{3}{|c|}{ Anal., Found (Calcd) $/ \%$} \\
\hline & & & ${ }^{\circ} \mathrm{C}^{\mathrm{a}}$ & $\mathrm{C}$ & $\mathrm{H}$ & $\mathrm{S}$ \\
\hline $\mathrm{C}_{12}{ }^{\mathrm{H}} 25^{-}$ & & & $53.5^{\mathrm{b}}$ & $\begin{array}{c}79.05 \\
(78.97)\end{array}$ & $\begin{array}{c}9.40 \\
(9.33)\end{array}$ & $\begin{array}{c}7.65 \\
(7.81)\end{array}$ \\
\hline & & & Oil & $\begin{array}{c}76.43 \\
(76.31)\end{array}$ & $\begin{array}{c}9.24 \\
(9.15)\end{array}$ & $\begin{array}{c}7.41 \\
(7.27)\end{array}$ \\
\hline & & & 67.0 & $\begin{array}{c}72.95 \\
(72.86)\end{array}$ & $\begin{array}{c}8.40 \\
(8.38)\end{array}$ & $\begin{array}{c}7.41 \\
(7.20)\end{array}$ \\
\hline & & & $36.5-37.0$ & $\begin{array}{c}71.27 \\
(71.17)\end{array}$ & $\begin{array}{c}8.13 \\
(8.18)\end{array}$ & $\begin{array}{c}7.30 \\
(7.04)\end{array}$ \\
\hline & & & 61.5 & $\begin{array}{c}81.11 \\
(80.82)\end{array}$ & $\begin{array}{c}8.86 \\
(8.75)\end{array}$ & $\begin{array}{c}7.08 \\
(6.96)\end{array}$ \\
\hline & & & 37.0 & $\begin{array}{c}79.10 \\
(79.19)\end{array}$ & $\begin{array}{c}9.54 \\
(9.49)\end{array}$ & $\begin{array}{c}7.76 \\
(7.55)\end{array}$ \\
\hline & & & $40.0^{\mathrm{c}}$ & $\begin{array}{c}76.52 \\
(76.31)\end{array}$ & $\begin{array}{c}9.12 \\
(9.15)\end{array}$ & $\begin{array}{c}7.31 \\
(7.27)\end{array}$ \\
\hline & & & 28.0 & $\begin{array}{c}76.40 \\
(76.31)\end{array}$ & $\begin{array}{c}9.18 \\
(9.15)\end{array}$ & $\begin{array}{c}7.16 \\
(7.27)\end{array}$ \\
\hline & & & $57.0-57.5$ & $\begin{array}{c}71.35 \\
(71.17)\end{array}$ & $\begin{array}{c}8.17 \\
(8.18)\end{array}$ & $\begin{array}{c}7.10 \\
(7.04)\end{array}$ \\
\hline & $\mathrm{CH}_{3}$ & & $\begin{array}{c}(168-172 / \\
0.06 \mathrm{mmHg})\end{array}$ & $\begin{array}{c}75.85 \\
(75.80)\end{array}$ & $\begin{array}{c}10.50 \\
(10.41)\end{array}$ & $\begin{array}{c}9.30 \\
(9.20)\end{array}$ \\
\hline & & & Oil & $\begin{array}{c}68.86 \\
(69.01)\end{array}$ & $\begin{array}{c}5.03 \\
(5.00)\end{array}$ & $\begin{array}{c}8.38 \\
(8.37)\end{array}$ \\
\hline HO- & & & $133-134$ & $\begin{array}{c}75.67 \\
(75.59)\end{array}$ & $\begin{array}{c}7.54 \\
(7.61)\end{array}$ & $\begin{array}{c}6.77 \\
(6.73)\end{array}$ \\
\hline
\end{tabular}

a Solid products were recrystallized from $\mathrm{MeOH}$.

b Lit. $^{20} \mathrm{mp} 52^{\circ} \mathrm{C}$.

c Lit. $^{20} \mathrm{mp} 41-41.5^{\circ} \mathrm{C}$.

mixture was passed through a column of silica gel and concentrated under reduced pressure. Repeated chromatography of the residue gave $1.70 \mathrm{~g}(77 \%$ yield) of IIIa: $[\alpha]_{\mathrm{D}}+6.31^{\circ}\left(c, 16.78 \mathrm{~g} 1^{-1}\right)(8 \% \mathrm{ee})$.

When $\mathrm{QN}$ was used as the catalyst in place of
AN-QN (9.7), the reaction was carried out for 13 days. The reaction mixture was washed with $0.1 \mathrm{~N}$ $\mathrm{HCl}$, and then with water until it became neutral. The toluene solution was dried over anhydrous $\mathrm{MgSO}_{4}$. Evaporation of the solvent followed by 
Table II. Asymmetric addition of thiols (RSH) to $\alpha, \beta$-unsaturated ketones $\left(\mathrm{R}^{\prime} \mathrm{CH}=\mathrm{CHCOAr}\right)$ catalyzed by $\mathrm{AN}-\mathrm{QN}(9.7)^{\mathrm{a}}$

\begin{tabular}{|c|c|c|c|c|c|}
\hline \multirow{2}{*}{$\begin{array}{c}\text { Thiol } \\
\text { R }\end{array}$} & \multicolumn{2}{|c|}{ Unsaturated ketone } & \multirow{2}{*}{$\frac{\text { Time }}{\text { day }}$} & \multirow{2}{*}{$\frac{\text { Yield }}{\%}$} & \multirow{2}{*}{$\frac{[\alpha]_{D}}{\operatorname{deg}^{b}}$} \\
\hline & $\mathrm{R}^{\prime}$ & Ar & & & \\
\hline \multirow[t]{10}{*}{$\mathrm{C}_{12}{ }^{\mathrm{H}} 25^{-}$} & & & 7 & 43 & +1.88 \\
\hline & & & 7 & 10 & +2.48 \\
\hline & & & 6 & 27 & -0.40 \\
\hline & & & 5 & 69 & 0.0 \\
\hline & & & 6 & 9 & -3.98 \\
\hline & & & 10 & 22 & +0.67 \\
\hline & & & 12 & 19 & +7.74 \\
\hline & & & 7 & 11 & +14.0 \\
\hline & & & 10 & 40 & -0.23 \\
\hline & & & 4 & 77 & +0.42 \\
\hline $\mathrm{Cl}-<$ & & & 17 & 82 & -4.25 \\
\hline HO- & & & 10 & 61 & +1.12 \\
\hline $\mathrm{Ph}_{3} \mathrm{C}-$ & & & 14 & 0 & \\
\hline
\end{tabular}

a Stirring in toluene at room temperature under $\mathrm{N}_{2}$.

b Measured in benzene at $25^{\circ} \mathrm{C}$.

chromatography of the residue gave $2.07 \mathrm{~g}(94 \%$ yield) of IIIa: $[\alpha]_{\mathrm{D}}-20.6^{\circ}\left(c, 16.88 \mathrm{gl}^{-1}\right)(26 \% \mathrm{oe})$.

Asymmetric Addition of $\mathbf{I}$ to $\mathbf{I l b}$. A mixture of $1.01 \mathrm{~g}$ of $\mathrm{I}, 1.30 \mathrm{~g}$ of $\mathbf{I I b}$, and $0.095 \mathrm{~g}$ of $\mathrm{AN}-\mathrm{QN}$ (10.8) in $30 \mathrm{ml}$ of toluene was stirred for 10 days. The reaction mixture was worked up as above to give $0.53 \mathrm{~g}(37 \%$ yield $)$ of IIIb: $[\alpha]_{\mathrm{D}}+4.36^{\circ}(c, 15.13$ $\mathrm{gl}^{-1}$ ); mp $53.5^{\circ} \mathrm{C}$ (lit. ${ }^{20} \mathrm{mp} 52^{\circ} \mathrm{C}$ ); IR $1682 \mathrm{~cm}^{-1}$ $\left(v_{\mathrm{C}=\mathrm{o}}\right)$; NMR $\left(\mathrm{CDCl}_{3}\right) \delta 0.8-1.8\left(\mathrm{~m}, 23 \mathrm{H}, \mathrm{C}_{11} \mathrm{H}_{23}\right)$, $2.33\left(\mathrm{t}, J=7 \mathrm{~Hz}, 2 \mathrm{H}, \mathrm{CH}_{2} \mathrm{~S}\right), 3.51(\mathrm{~d}, J=7 \mathrm{~Hz}, 2 \mathrm{H}$, $\left.\mathrm{CH}_{2} \mathrm{CO}\right), 4.53(\mathrm{t}, J=7 \mathrm{~Hz}, 1 \mathrm{H}, \mathrm{CHS}), 7.0-8.0 \mathrm{ppm}$ $(\mathrm{m}, 10 \mathrm{H}$, aromatic protons). Analytical data are listed in Table I.

Asymmetric Addition of $\mathbf{I}$ to IIc. A mixture of $1.01 \mathrm{~g}$ of I, $0.91 \mathrm{~g}$ of IIc, and $0.10 \mathrm{~g}$ of AN-QN (9.7) in $30 \mathrm{ml}$ of toluene was stirred for 4 days. The reaction mixture was worked up to give, after chromatography, $1.34 \mathrm{~g}(77 \%$ yield $)$ of IIIc: $[\alpha]_{\mathrm{D}}$ $+0.42^{\circ}\left(c, 18.99 \mathrm{gl}^{-1}\right)$; bp $168-172^{\circ} \mathrm{C}(0.06$ $\mathrm{mmHg})$; IR $1695 \mathrm{~cm}^{-1}\left(v_{\mathrm{C}=\mathrm{o}}\right)$; NMR $\left(\mathrm{CDCl}_{3}\right)$ $\delta 0.7-1.7\left(\mathrm{~m}, 26 \mathrm{H}, \mathrm{C}_{11} \mathrm{H}_{23}+\mathrm{CH}_{3}\right), 2.40(\mathrm{t}, J=7 \mathrm{~Hz}$, $\left.\mathrm{CH}_{2} \mathrm{~S}\right), 2.8-3.4\left(\mathrm{~m}, 3 \mathrm{H}, \mathrm{SCHCH}_{2} \mathrm{CO}\right), 7.2-7.9 \mathrm{ppm}$ 
(m, 5H, aromatic protons). Analytical data are listed in Table I.

Asymmetric Addition of p-Chlorothiophenol to IIa. A mixture of $0.72 \mathrm{~g}$ of $p$-chlorothiophenol, $1.49 \mathrm{~g}$ of IIa, and $0.10 \mathrm{~g}$ of $\mathrm{AN}-\mathrm{QN}$ (9.7) in $30 \mathrm{ml}$ of toluene was stirred for 17 days. The workup of the reaction mixture and elution of the crude product on silica gel gave $1.56 \mathrm{~g}(82 \%$ yield) of 2-(4-chlorophenylthio)-2-(2-methoxyphenyl)ethyl phenyl ketone as a viscous oil: $[\alpha]_{\mathrm{D}}-4.25^{\circ}\left(c, 17.40 \mathrm{gl}^{-1}\right)$; IR 1693 $\mathrm{cm}^{-1}\left(v_{\mathrm{C}=0}\right) ; \operatorname{NMR}\left(\mathrm{CDCl}_{3}\right) \delta 3.61(\mathrm{~d}, J=7 \mathrm{~Hz}, 2 \mathrm{H}$, $\mathrm{CH}_{2} \mathrm{CO}$ ), 3.80 (s, $3 \mathrm{H}, \mathrm{CH}_{3} \mathrm{O}$ ), 5.33 (t, $J=7 \mathrm{~Hz}, 1 \mathrm{H}$, CHS), $6.6-8.0 \mathrm{ppm}(\mathrm{m}, 13 \mathrm{H}$, aromatic protons). The analytical data are given in Table $\mathrm{I}$.

\section{Synthesis of Racemic IIIa}

A solution of $4.04 \mathrm{~g}(20 \mathrm{mmol})$ of I, $5.95 \mathrm{~g}(25$ $\mathrm{mmol})$ of IIa, and $0.11 \mathrm{~g}(1 \mathrm{mmol})$ of triethylenediamine in $120 \mathrm{ml}$ of toluene was refluxed for $41 \mathrm{~h}$ under $\mathrm{N}_{2}$. The reaction mixture was extracted three times with $25 \mathrm{ml}$ portions of $0.1 N \mathrm{HCl}$, washed with water, and then dried over anhydrous $\mathrm{MgSO}_{4}$. Evaporation of the toluene under reduced pressure followed by column chromatography of the residue gave $3.28 \mathrm{~g}$ ( $37 \%$ yield) of racemic IIIa as a viscous oily material. the NMR spectrum of this material was identical with that of the optically active sample described earlier.

\section{RESULTS AND DISCUSSION}

Initially, various reactions between a thiol and an $\alpha, \beta$-unsaturated ketone were studied in a search for suitable reactant combinations that would show the effect of the $\beta$-substituent on the stereochemistry. These reactions were carried out in toluene at room temperature using $\mathrm{AN}-\mathrm{QN}$ (9.7) (the figures in parenthesis indicate the alkaloid content of the copolymer in $\mathrm{mol}^{\mathrm{o}} \mathrm{o}$ ). The results are summarized in Table II. The reactions were sluggish but gave optically active products in most cases. Almost all of the products were new compounds whose structures were established by elemental analyses (Table I) and ${ }^{1} \mathrm{H}$ NMR and infrared (IR) spectra. The IR spectra of the products were in agreement with the proposed structures; the carbonyl stretching frequencies occurred at $1650-1673 \mathrm{~cm}^{-1}$ in the starting $\alpha, \beta$ unsaturated ketones and they shifted to $1675-1695$ $\mathrm{cm}^{-1}$ in the adducts, due to a loss in conjugation. The NMR spectra exhibited a doublet at $\delta 3.42-$
$3.61 \mathrm{ppm}(2 \mathrm{H})$ owing to the methylene protons adjacent to carbonyl group and a triplet at $\delta 4.45-$ $5.29 \mathrm{ppm}(1 \mathrm{H})$ due to the methine proton linked to sulfur. The only exception was the product of the dodecanethiol (I)-crotonophenone (IIc) reaction, which showed complex signals of $\mathrm{SCHCH}_{2} \mathrm{CO}$ in the region $\delta 2.8-3.4 \mathrm{ppm}$.

Of the thirteen runs in Table II, the combination of $\mathbf{I}$ and 2-methoxychalcone (IIa) gave a product with the highest optical rotation. This combination had the additional advantage that the enantiomeric excess $(\%$ ee) of the product (IIIa) could be determined by NMR spectroscopy (vide infra). Furthermore, the bulky 2-methoxyphenyl group was expected to exert a marked influence on the stereochemical course of the reaction. Accordingly, we investigated the asymmetric addition of I to IIa as fully as possible. In order to examine the steric effect of $\beta$-substituents, asymmetric reactions of $\mathbf{I}$ with chalcone (IIb) and IIc were also studied.

$$
\begin{aligned}
& \mathrm{C}_{12} \mathrm{H}_{25} \mathrm{SH}+\mathrm{R}^{\prime} \mathrm{CH}=\mathrm{CHCOPh} \stackrel{\substack{\text { Cata- } \\
\text { lyst* }}}{\longrightarrow} \mathrm{C}_{12} \stackrel{\mathrm{R}^{\prime}}{\mathrm{R}_{25}} \stackrel{1}{\mathrm{SCHCH}_{2}} \mathrm{COPh} \\
& \text { I IIa } \mathrm{R}^{\prime}=\mathrm{OCH}_{3} \\
& \text { b } \mathrm{R}^{\prime}=\square \\
& \text { c } \mathrm{R}^{\prime}=\mathrm{CH}_{3}- \\
& \text { IIIa } \mathrm{R}^{\prime}=\mathrm{OCH}_{3} \\
& \text { b } \mathrm{R}^{\prime}= \\
& \text { c } \mathrm{R}^{\prime}=\mathrm{CH}_{3}-
\end{aligned}
$$

\section{Asymmetric Addition of I to IIa}

The reaction of $\mathbf{I}$ to IIa was carried out in certain solvents other than toluene, using $\mathrm{AN}-\mathrm{QN}(9.7)$ as the catalyst (Table III). In chloroform, the reaction was as sluggish as in toluene, and the extent of asymmetric induction was somewhat lower. The reaction in DMF proceeded homogeneously and quite smoothly, but gave a lower enantiomeric yield. With the protic ethanol solvent, the lowest enantiomeric yield was obtained. Thus, toluene was used as the solvent in subsequent experiments.

When racemic IIIa, synthesized independently with triethylenediamine catalyst (see EXPERIMENTAL Section), was treated with AN-QN (9.7) in toluene for 10 days, the recovered sample of IIIa was optically inactive. This finding ruled out the possibility of asymmetric adsorption of IIIa by the catalyst under the conditions employed. 
Table III. Asymmetric addition of I to IIa catalyzed by AN-QN $(9.7)^{\mathrm{a}}$

\begin{tabular}{|c|c|c|c|c|}
\hline \multirow{2}{*}{ Solvent } & Time & Yield & {$[\alpha]_{\mathrm{D}}$} & \multirow{2}{*}{$\%$ ee } \\
\hline & day & $\%$ & $\operatorname{deg}^{b}$ & \\
\hline Toluene & 7 & 11 & +14.0 & 18 \\
\hline Chloroform & 16 & 26 & +13.6 & 17 \\
\hline DMF & 1 & 77 & +6.31 & 8 \\
\hline Ethanol & 6 & 66 & +4.17 & 5 \\
\hline
\end{tabular}

a Stirring at room temperature under $\mathrm{N}_{2}$.

b Measured in benzene at $25^{\circ} \mathrm{C}$.

Table IV. Asymmetric addition of $\mathbf{I}$ to $\mathbf{I I a}^{\mathbf{a}}$

\begin{tabular}{|c|c|c|c|c|c|c|}
\hline \multirow{2}{*}{ Entry } & \multicolumn{2}{|c|}{ Catalyst } & \multirow{2}{*}{$\frac{\text { Time }}{\text { day }}$} & \multirow{2}{*}{$\frac{\text { Yield }}{\%}$} & \multirow{2}{*}{$\frac{[\alpha]_{D}}{\operatorname{deg}^{d}}$} & \multirow{2}{*}{$\%$ ee } \\
\hline & type $^{b}$ & $\eta_{\mathrm{inh}}^{\mathrm{c}}$ & & & & \\
\hline 1 & $\begin{array}{l}\mathrm{AN}-\mathrm{QN} \\
(10.8)\end{array}$ & 0.149 & 12 & 21 & +16.0 & 20 \\
\hline 2 & $\begin{array}{l}\mathrm{AN}-\mathrm{QN} \\
(6.0)\end{array}$ & 0.200 & 7 & 11 & +14.0 & 18 \\
\hline 3 & $\begin{array}{l}\mathrm{AN}-\mathrm{QN} \\
(6.0)\end{array}$ & 0.293 & 9 & 18 & +13.6 & 17 \\
\hline 4 & $\begin{array}{l}\text { AN-QD } \\
(9.8)\end{array}$ & 0.176 & 9 & 31 & +6.12 & 8 \\
\hline 5 & $\begin{array}{l}\text { AN-CD } \\
(6.1)\end{array}$ & 0.286 & 11 & 31 & +2.85 & 4 \\
\hline 6 & $\begin{array}{l}\mathrm{AN}-\mathrm{CN} \\
(2.4)\end{array}$ & 0.270 & 9 & 31 & +9.33 & 12 \\
\hline 7 & $\begin{array}{l}\mathrm{AN}-\mathrm{QN} \cdot \mathrm{HCl} \\
(6.9)\end{array}$ & 0.222 & 12 & 34 & +0.16 & 0 \\
\hline 8 & $\begin{array}{l}\text { AN-QNBC } \\
(3.2)\end{array}$ & 0.236 & 12 & 22 & -0.08 & 0 \\
\hline 9 & $\begin{array}{l}\text { AN-QNEC } \\
(9.9)\end{array}$ & 0.230 & 11 & 20 & +7.34 & 9 \\
\hline 10 & $\mathrm{QN}$ & 13 & 94 & -20.6 & 26 & \\
\hline 11 & DHQN & 3 & 85 & -21.0 & 27 & \\
\hline 12 & QD & 13 & 83 & +31.6 & 40 & \\
\hline 13 & DHQD & 3 & 93 & +34.2 & 44 & \\
\hline 14 & $\mathrm{CD}$ & 6 & 66 & -16.0 & 20 & \\
\hline 15 & DHCD & 3 & 44 & -12.6 & 16 & \\
\hline 16 & $\mathrm{CN}$ & 6 & 50 & +15.9 & 20 & \\
\hline 17 & DHCN & 3 & 44 & +23.7 & 30 & \\
\hline
\end{tabular}

a Stirring in toluene at room temperature under $\mathrm{N}_{2}$.

b The figures in parentheses indicate the alkaloid content of the copolymer in $\mathrm{mol}_{\%} \%$.

c Measured in benzene at $25^{\prime \prime} \mathrm{C}$.

d Measured in benzene at $25^{\circ} \mathrm{C}$.
The results of the asymmetric addition with various kinds of catalysts, AN-CA, cinchona alkaloid (CA), and dihydro derivatives of $\mathrm{CA}$ (DHCA), are listed in Table IV. The most important observation from Table IV is that the unmodified AN-CA catalysts always gave an excess of (+)-IIIa irrespective of the kind of the alkaloid units incorporated (entries 1-6). This is the second example of the C(3)-control. With low-molecularweight CA and DHCA catalysts, the reaction was $\mathrm{C}(8), \mathrm{C}(9)$-control; the $\mathrm{QN}$ and $\mathrm{CD}$ series (entries 10,11 and 14,15) gave (-)-enantiomer in excess, while the QD and CN series (entries 12, 13 and 16, 17) gave (+)-enantiomer in excess. In this respect, this reaction is very similar to that of benzyl mercaptan with 2-nitrostyrene. ${ }^{3}$ In the present case, however, the monomeric catalysts gave much higher enantiomeric yields than the polymeric catalysts.

The $\mathrm{CA}^{\prime}$ content in the copolymer affected the enantiomeric yield to some extent. For AN-QN copolymers, increasing the $\mathrm{QN}$ content tends to increase the enantiomeric yield. Modification of the amino group $(\mathrm{QN} \cdot \mathrm{HCl}, \mathrm{QNBC})$ or the hydroxyl group (QNEC) of the QN unit reduced the extent of asymmetric induction (entries 7-9). Especially, amino-modified copolymers gave almost optically inactive products, a fact indicating the importance of the free amino group in the asymmetric catalysis.

The enantiomeric excess of IIIa was determined by NMR spectroscopy. Addition of $\mathrm{Eu}(\mathrm{TFC})_{3}$ (30 $\mathrm{mol}^{\%}$ ) to $\mathrm{CDCl}_{3}$ solution of IIIa gave rise to two separated singlets for the methyl group linked to

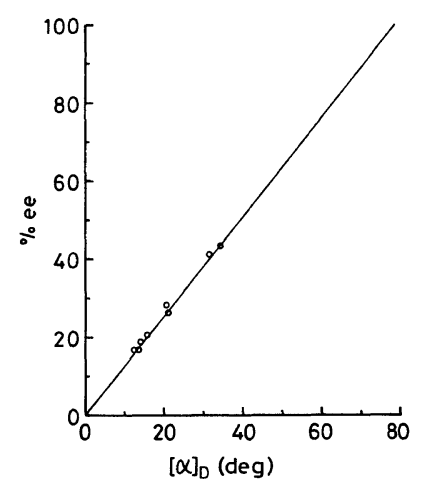

Figure 1. Percent ee- $[\alpha]_{D}$ relationship for IIIa. 
oxygen. Figure 1 shows the $\%$ ee- $[\alpha]_{D}$ relationship. From the data the $[\alpha]_{D}^{25}$ (benzene) value of optically pure IIIa was calculated as $78.6 \pm 1.8^{\circ}$ by the leastsquares method. The $\%$ ee values of the reaction products listed in Tables III and IV are based on their optical rotations.

Table V. Asymmetric addition of I to IIb ${ }^{\mathbf{a}}$

\begin{tabular}{|c|c|c|c|}
\hline \multirow{2}{*}{ Catalyst $^{\mathrm{b}}$} & Time & Yield & {$[\alpha]_{\mathrm{D}}$} \\
\hline & day & $\%$ & $\operatorname{deg}^{\mathrm{c}, \mathrm{d}}$ \\
\hline AN-QN (10.8) & 10 & 37 & +4.36 \\
\hline AN-QD (9.8) & 13 & 26 & +6.15 \\
\hline $\mathrm{AN}-\mathrm{CD}(6.1)$ & 10 & 41 & -2.77 \\
\hline $\mathrm{AN}-\mathrm{CN}(2.4)$ & 11 & 44 & +9.33 \\
\hline QN & 4 & 78 & -26.2 \\
\hline QD & 5 & 86 & +36.7 \\
\hline $\mathrm{CD}$ & 4 & 42 & -27.7 \\
\hline $\mathrm{CN}$ & 4 & 62 & +18.5 \\
\hline
\end{tabular}

a Stirring in toluene at room temperature under $\mathrm{N}_{2}$.

b The figures in parentheses indicate the alkaloid content of the copolymer in $\mathrm{mol} \%$.

c Measured in benzene at $25^{\circ} \mathrm{C}$.

d Enantiomeric excess and absolute configuration are unknown.

Table VI. Asymmetric addition of I to II $\mathbf{c}^{\mathrm{a}}$

\begin{tabular}{|c|c|c|c|}
\hline \multirow{2}{*}{ Catalyst $^{\mathrm{b}}$} & Time & Yield & {$[\alpha]_{\mathrm{D}}$} \\
\hline & day & $\%$ & $\operatorname{deg}^{c, d}$ \\
\hline AN-QN (9.7) & 4 & 77 & +0.42 \\
\hline $\mathrm{AN}-\mathrm{QD}(9.3)^{\mathrm{e}}$ & 4 & 74 & -0.82 \\
\hline $\mathrm{AN}-\mathrm{CD}(7.9)^{\mathrm{f}}$ & 4 & 72 & +0.07 \\
\hline $\mathrm{AN}-\mathrm{CN}(2.4)$ & 4 & 71 & -0.59 \\
\hline QN & 1 & 83 & +0.66 \\
\hline DHQN & 1 & 77 & +1.07 \\
\hline QD & 1 & 79 & -0.76 \\
\hline DHQD & 1 & 76 & -1.41 \\
\hline $\mathrm{CD}$ & 1 & 78 & +0.53 \\
\hline DHCD & 1 & 76 & +0.43 \\
\hline $\mathrm{CN}$ & 1 & 75 & -0.40 \\
\hline $\mathrm{DHCN}$ & 1 & 76 & -0.13 \\
\hline
\end{tabular}

a Stirring in toluene at room temperature under $\mathrm{N}_{2}$.

b The figures in parentheses indicate the alkaloid content of the copolymer in $\mathrm{mol}^{\circ}$.

c Measured in benzene at $25^{\circ} \mathrm{C}$.

${ }^{d}$ Enantiomeric excess and absolute configuration are unknown.

e $\eta_{\text {inh }} 0.233\left(c, 5.0 \mathrm{gl}^{-1} ; \mathrm{DMF}, 30^{\circ} \mathrm{C}\right)$.

${ }^{\mathrm{f}} \eta_{\text {inh }} 0.352\left(c, 5.0 \mathrm{gl}^{-1} ; \mathrm{DMF}, 30^{\circ} \mathrm{C}\right)$.

\section{Asymmetic Addition of $\mathbf{I}$ to $\mathbf{I I b}$ and $\mathbf{I I}$}

The asymmetric addition of I to IIb and IIc was also carried out in toluene at room temperature. Although the extent of asymmetric induction could not be determined for these reactions, the rotational signs of the products (IIIb and IIIc) are sensitive indication of the stereochemistry.

With IIb as the Michael acceptor, the results were somewhat complex (Table V). AN-QN and AN-QD each having a methoxy group at $C\left(6^{\prime}\right)$ gave the same enantiomer in excess, while $\mathrm{AN}-\mathrm{CD}$ and $\mathrm{AN}-\mathrm{CN}$, without the $\mathrm{C}\left(6^{\prime}\right)$-methoxy group, gave the opposite enantiomer in excess. Here, the $C\left(6^{\prime}\right)$ substituent is important in determining the mode of stereoregulation. Monomeric CA catalysts gave better enantiomeric yields than $\mathrm{AN}-\mathrm{CA}$, and the rotational signs reflect the configurations at $\mathrm{C}(8)$ and $\mathrm{C}(9)$.

With IIc as the Michael acceptor, the reaction was $\mathrm{C}(8), \mathrm{C}(9)$-control, irrespective of whether the catalyst was monomeric or polymeric (Table VI).

\section{Relation between Steric Factors and the Mode of Stereoregulation}

Table VII summarizes the stereochemical results of the asymmetric addition of I to IIa-IIc. With monomeric catalysts, all the reactions were $C(8)$, $\mathrm{C}(9)$-control. On the other hand, with AN-CA catalysts, the mode of stereoregulation varied, depending not only on the $\beta$-substituent ( $\left.\mathrm{R}^{\prime}\right)$ but also on the $C\left(6^{\prime}\right)$-substituent. Small $R^{\prime}$ preferred the $\mathrm{C}(8), \mathrm{C}(9)$-control, while large $\mathrm{R}^{\prime}$ preferred the C(3)-control. The reaction of I with IIb was the

Table VII. Stereochemical results of asymmetric addition of $\mathbf{I}$ to IIa-IIc $\left(\mathrm{R}^{\prime} \mathrm{CH}=\mathrm{CHCOPh}\right)$

\begin{tabular}{|c|c|c|}
\hline $\mathbf{R}^{\prime}$ & Catalyst & Mode of stereoregulation \\
\hline & $\begin{array}{l}3 \\
\text { Monomeric } \\
\text { AN-CA }\end{array}$ & $\begin{array}{l}\mathrm{C}(8), \mathrm{C}(9) \text {-control } \\
\mathrm{C}(3) \text {-control }\end{array}$ \\
\hline & $\begin{array}{l}\text { Monomeric } \\
\text { AN-CA }\end{array}$ & $\begin{array}{l}\mathrm{C}(8), \mathrm{C}(9) \text {-control } \\
\left.\mathrm{C}(3) \text {-control [if } \mathrm{CH}_{3} \mathrm{O}-\mathrm{C}\left(6^{\prime}\right)\right] \\
\mathrm{C}(8), \mathrm{C}(9) \text {-control }\left[\text { if } \mathrm{H}-\mathrm{C}\left(6^{\prime}\right)\right]\end{array}$ \\
\hline $\mathrm{CH}_{3}-$ & $\begin{array}{l}\text { Monomeric } \\
\text { AN-CA }\end{array}$ & $\begin{array}{l}\mathrm{C}(8), \mathrm{C}(9) \text {-control } \\
\mathrm{C}(8), \mathrm{C}(9) \text {-control }\end{array}$ \\
\hline
\end{tabular}


intermediate case, where both $\mathrm{C}(8), \mathrm{C}(9)$-control and $\mathrm{C}(3)$-control were observed depending on the $\mathrm{C}\left(6^{\prime}\right)$-substituent. These results clearly show that the $\mathrm{C}(3)$-control is closely related to the steric crowdings, and becomes the predominant factor in determining the stereochemistry when the steric environments of the enantioface differentiating step are sufficiently crowded.

\section{Reaction Pathway}

The pathway of the asymmetric reactions of thiols with $\alpha, \beta$-unsaturated systems is outlined in Scheme $\mathrm{I}$, where $\mathrm{Q}$ represents the quinoline ring. The first

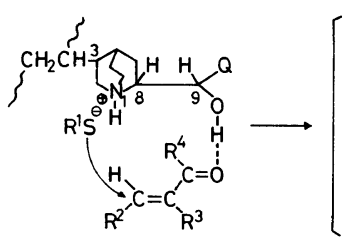

IV

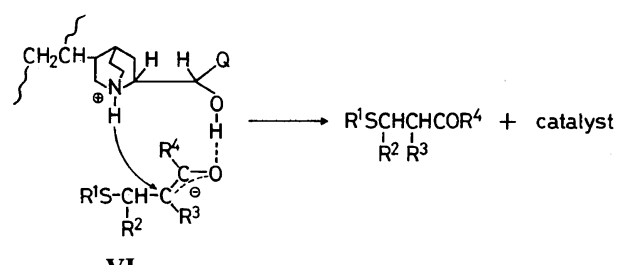

Scheme I.

step in the reaction is the proton abstraction from thiol by N(1)-nitrogen. It may be said that a hydrogen bond exists between the hydroxyl group of the catalyst and the oxygen atom of the $\alpha, \beta$ unsaturated compound, thereby leading to a more structured state, since a lack of free hydroxyl groups in the catalyst usually results in a diminished enantiomeric yield in both Type I and Type II reactions (see Table IV and ref 1 and 3 ). The thiolate anion $\left(\mathbf{R}^{1} \mathbf{S}^{\ominus}\right)$ attacks the $\beta$-carbon (IV). The stereochemistry of the Type II reactions $\left(\mathbf{R}^{2}\right.$ is not hydrogen) is determined in this step. Since three molecules (the protonated catalyst, $\mathbf{R}^{1} \mathrm{~S}^{\ominus}$, and the unsaturated compound) participate in structure IV, the attacking direction of $\mathrm{R}^{1} \mathrm{~S}^{\ominus}$ is subject to steric hindrance. Our results show that when both the $\mathrm{C}(3)$-substituent and $\mathrm{R}^{2}$ are bulky enough (combination of AN-CA catalyst and IIa), the direction of $\mathrm{R}^{1} \mathrm{~S}^{\ominus}$ attack is more strongly controlled by the configuration at $\mathrm{C}(3)$ rather than by the con- figurations at $\mathrm{C}(8)$ and $\mathrm{C}(9)$, resulting in the formation of the same enantiomer, regardless of the kind of alkaloid moiety. If the steric bulkiness of either the $\mathrm{C}(3)$-substituent or $\mathrm{R}^{2}$ is small (monomeric catalyst or IIc), the chiral force stemming from $\mathrm{C}(3)$ does not exceed those from $\mathrm{C}(8)$ and $\mathrm{C}(9)$. The transition-state structure may be depicted as $\mathbf{V}$. In the Type I reactions, $\left(\mathrm{R}^{2}\right.$ is hydrogen and $\mathrm{R}^{3}$ is not), the stereochemistry is determined at the step of protonation to the $\alpha$-carbon (VI). Only two molecules participate in this step. Furthermore, proton migration is the only action. Accordingly, this step is relatively insensitive to steric hindrance, and the direction of protonation is controlled by the configurations at the nearest chiral carbons, $\mathrm{C}(8)$ and $C(9)$.

\section{SUMMARY}

The mode of stereoregulation in the AN-CA catalyzed Type II reactions varied, depending on the $\beta$-substituent of the acceptor. The $\mathrm{C}(3)$-control was observed only when the steric environments of the enantioface differentiating step were sufficiently crowded. With monomeric catalysts, the reactions were always $C(8), C(9)$-control, regardless of the kind of $\beta$-substituent. The steric bulkiness of the thiol may also affect the stereochemistry of the $\mathrm{AN}-\mathrm{CA}$ catalyzed reactions, but this point must await further study.

\section{REFERENCES}

1. N. Kobayashi and K. Iwai, Macromolecules, 13, 31 (1980).

2. N. Kobayashi and K. Iwai, J. Polym. Sci., Polym. Lett. Ed., 18, 417 (1980).

3. N. Kobayashi and K. Iwai, Tetrahedron Lett., 21, 2167 (1980).

4. G. Berti and A. Marsili, Tetrahedron, 22, 2977 (1966).

5. O. Cervinka and O. Bělovský, Collect. Czech. Chem. Commun., 32, 3897 (1967).

6. G. Marchese, F. Naso, and L. Ronzini, J. Chem. Soc., Chem. Commun., 830 (1974).

7. D. Cararet and Z. Welvart, J. Organomet. Chem., 78, 295 (1974).

8. L. Meurling, Chemica Scripta, 7, 90 (1975).

9. H. Wynberg and R. Helder, Tetrahedron Lett., 4057 (1975).

10. H. Pracejus, F. W. Wilcke, and K. Hanemann, $J$. Prakt. Chem., 319, 219 (1977).

11. Y. Okamoto, K. Urakawa, K. Ohta, and H. Yuki, 


\section{Asymmetric Catalysis of Polymeric Alkaloids}

Macromolecules, 18, 923 (1980).

12. N. Kobayashi and K. Iwai, J. Polym. Sci., Polym. Chem. Ed., 18, 923 (1980).

13. N. Kobayashi and K. Iwai, J. Polym. Sci., Polym. Chem. Ed., 18, 223 (1980).

14. T. Fujisawa, K. Hata, and T. Kojima, Synthesis, 38 (1973).

15. W. Davey and J. R. Gwilt, J. Chem. Soc., 1008 (1957).
16. A. Maccioni and E. Marongiu, Ann. Chim. (Rome), 50, 1806 (1960); Chem. Abstr., 55, 17588d (1961).

17. V. Hanzlík and A. Bianchi, Ber., 32, 2282 (1899).

18. F. J. Pond and A. S. Shoffstall, J. Am. Chem. Soc., 22, 658 (1900).

19. H. Stobe and F. J. Wilson, J. Chem. Soc., 97, 1722 (1910).

20. F. Kipnis and J. Ornfelt, J. Am. Chem. Soc., 71, 3554 (1949). 